\title{
LIÇÕES SOBRE A SINTAXE HISTÓRICA DO INFINITIVO PORTUGUÊS
}

\author{
Marcos Martinho dos Santos*
}

Resumo: Exponho a sintaxe histórica do infinitivo final e do infinitivo objetivo do português, partindo da sintaxe histórica do infinitivo latino. Este, originalmente forma nominal pura, isto é, ablativo ou dativo de nome de ação, emprega-se como adjunto adverbial de finalidade. Tratado posteriormente como nome neutro indeclinável, passa a construir-se como objeto direto. Ilustro a exposição com exemplos de autores da língua latina e portuguesa; em particular da Demanda do Santo Graal e de Os Lusíadas de Camões.

Palavras-chave: Sintaxe histórica do infinitivo português; infinitivo final; infinitivo objetivo.

Abstract: I deal with the historical syntax of the infinitive of purpose and complementary infinitive in Portuguese. In order to do that, I begin with the historical syntax of the Latin infinitive. This infinitive originally is a pure noun form, or rather, an ablative or dative of an action name, so that it is used to indicate the purpose of the verbal action. It subsequently is treated as an indeclinable neuter noun, so that it completes the meaning of a verb. I illustrate my exposition by quoting from many authors in Latin and in Portuguese, mostly, from the Demanda do Santo Graal and Camões' Os Lusíadas.

Keywords: Historical syntax of Portuguese infinitive; infinitive of purpose; complementary infinitive.

* Universidade de São Paulo. 


\section{Introdução ${ }^{1}$}

A sintaxe do infinitivo latino e português é de natureza mista, quer dizer, apresenta a um só tempo índices verbais e nominais (MEILLET \& VENDRYES, 1979, p. 620-621). Índice verbal da sintaxe do infinitivo é, por exemplo, a capacidade deste de construir-se em latim com complemento acusativo e em português com complemento que se ligue ao infinitivo sem o auxílio de preposição. É certo que tal comportamento sintático depende da regência do infinitivo, mas o que importa é que nenhum complemento acusativo pode unir-se a nome; se tal ocorrer, a palavra a que se liga o complemento será verbo. Outro índice que denuncia a natureza verbal do infinitivo é a capacidade deste de construir-se em latim com nominativo e em português com sujeito. Novamente, tal comportamento sintático depende da pessoalidade do infinitivo - o infinitivo português chover, por exemplo, constróise por via de regra sem sujeito -, mas o que importa é que, se fosse nome puro, o infinitivo não admitiria tal construção. A par dos verbais, o índice que bem atesta a natureza nominal do infinitivo é a capacidade deste de exercer função de nome - mais precisamente, uma função de substantivo -, isto é, de comportarse como núcleo de funções tais como sujeito, complemento ou adjunto de verbo, ou complemento, adjunto ou aposto de nome. Além disso, vê-se clara a natureza nominal do infinitivo quando este é núcleo de sintagma preposicional, isto é, quando se prende a outra palavra (= verbo ou nome) por meio de preposição.

\footnotetext{
${ }^{1}$ Este artigo, sob a forma de conferência, foi exposto em outubro de 2006, primeiro, na Université de Lyon 2, a convite da Profa. Dra. Anne-Marie Pascal; depois, na Université de Lille 3 (Charles de Gaulle), a convite da Profa. Dra. Olinda Kleiman; enfim, na Université de Paris X (Nanterre), a convite da Profa. Dra. Idelette Muzart. As três apresentações contaram com o apoio da Fundação Calouste Gulbenkian, o qual devo à acolhida do Prof. Dr. João Pedro Garcia e à intervenção da Profa. Dra. Olinda Kleiman.
} 
Dos muitos e vários usos do infinitivo português, exponho a seguir a história do infinitivo final e a do infinitivo objetivo. $\mathrm{O}$ interesse do infinitivo final explica-se, porque remonta ao mais antigo uso, ou, se se quiser, ao uso mais original do infinitivo latino, do qual dependem direta ou indiretamente os demais usos. $\mathrm{O}$ interesse do infinitivo objetivo, por sua vez, explica-se, porque revela como o infinitivo, que originalmente se comportava como nome puro, passou a comportar-se como forma mista, isto é, a um só tempo nominal e verbal. De fato, a história do infinitivo revela, entre outras coisas, que o infinitivo, hoje paradigma da conjugação verbal do português, outrora foi tão-só forma nominal do latim.

Para tanto, sigo princípios de sintaxe estrutural para examinar as relações entre a forma do infinitivo e a função deste na oração, e também princípios de gramática histórica para examinar o modo como o uso final e o uso objetivo do infinitivo latino passaram ao português, em que se desenvolveu o emprego do infinitivo preposicional, e também o emprego do infinitivo em locução verbal. Ilustro ambos os usos com exemplos de autores do latim e do português; em particular, com passos da Demanda do Santo Graal e com versos de Os Lusíadas de Camões. ${ }^{2}$

\section{Da fonética e morfologia à sintaxe}

O comportamento sintático mais antigo do infinitivo latino depende da natureza morfológica original deste. Ora, na origem, o infinitivo latino é nome de ação, ou melhor, substantivo derivado de radical verbal por meio de sufixo nominal, ao qual se prendem desinências nominais. O sufixo nominal é o sufixo -s-, e as desinências nominais são as desinências casuais de ablativo em $e$ ou de dativo em - $i$ (MEILLET \& VENDRYES, 1979, p. 356-357; BUCK, 1962, p. 305-306). A pronúncia do sufixo -s- varia de acordo

\footnotetext{
${ }^{2}$ Os exemplos da Demanda foram extraídos de Demanda (1988), e os de Os Lusíadas, de Camões (1982).
} 
com a natureza fonética do radical verbal a que se prende. Assim, se se prende a radical verbal temático, ocupa posição intermediária entre a vogal temática do radical e a vogal - $e$ ou $-i$ da desinência, isto é, ocupa posição intervocálica; de acordo com a lei do rotacismo, porém, $\mathrm{o} / \mathrm{s} /$ intervocálico passa a $/ \mathbf{r} /:$ am-a-s-e $>$ am-a-r-e; deb-e-s-e $>$ deb-e-r-e. Se se prende, porém, a radical atemático, ocupa posição intermediária entre a consoante do radical e a vogal da desinência; logo, por não ocupar posição intervocálica, o /s/ não passa a /r/, mas, por ser precedido de som consonantal, é assimilado a este: uel-s-e $>$ uel-l-e;fer-s-e $>$ fer-r-e. Em suma, a pronúncia do sufixo -smantém-se apenas quando se prende a radical temático em -s-, que não só não é som vocálico que o obrigue ao rotacismo, mas tampouco é som consonantal diferente que o constranja à assimilação; por isso, o -s- de es-s-e não evoluciona. Em português, o som vocálico da desinência cai, isto é, sofre apócope, de modo que, se amase e debese, em latim, passam a amare e debere, estas, em português, passam a amar e dever. ${ }^{3}$

As desinências casuais de ablativo em $-e$ e dativo em $-i$ têm a forma das desinências de ablativo e dativo dos nomes da $3^{\text {a }}$ declinação do latim, isto é, dos nomes de radical atemático, justamente porque se prendem ao sufixo $-s$-, isto é, a som consonantal, e não a vogal temática (ERNOUT, 1974, 14-15 e 35; MEILLET \& VENDRYES, 1979, p. 451-453). Quanto ao valor, a desinência do ablativo tem, originalmente, valor instrumental, e a do dativo, valor final; com o tempo, porém, este acabou por contaminar aquele (ERNOUT \& THOMAS, 1953, p. 260).

Em suma, na origem, o infinitivo não só não é verbo, mas tampouco é forma nominal do verbo; ao contrário, é forma nominal pura. Em particular, é nome de ação que se declina no ablativo ou

\footnotetext{
${ }^{3}$ Atente-se para a evolução do lat. esse ao it. essere, que se explica por analogia. Pois, depois que a terminação - $r(e)$ se impôs como paradigma morfológico do infinitivo, $o$ infinitivo latino esse foi tratado como radical a que se devia prender aquela terminação, à semelhança, por exemplo, do radical ama-, assim: ama- $\rightarrow$ ama-re :: esse- $\rightarrow$ esse-re.
} 
dativo de finalidade. Daí, deduz-se o comportamento sintático original do infinitivo: como nome, não admite sujeito; como ablativo ou dativo de finalidade, prende-se a verbos de finalidade e outros semelhantes, a fim de expressar a finalidade da ação que, por sua vez, é expressa pelo verbo. Em outras palavras, o comportamento sintático original do infinitivo latino é o de adjunto adverbial de finalidade (ERNOUT \& THOMAS, 1953, p. 260).

\section{Infinitivo final}

Como adjunto adverbial de finalidade, o infinitivo constrói-se com verbos associados à idéia de finalidade, seja no sentido concreto de direção, seja no sentido abstrato de intenção. No primeiro caso, o infinitivo prende-se a verbos de movimento (= uerba eundi: lat. ire, exire, uenire; port. ir, vir); no segundo, a verbos de finalidade (= uerba mittendi: lat. mittere, agere; port. enviar) ou de doação (= uerba donandi: lat. dare, tradere, ministrare; port. dar).

Em latim, o infinitivo final, por ser, como disse, espécie original de infinitivo, já é testemunhado nos sécs. III-II a.C., por exemplo, por Terêncio, Catão e Plauto:

a) com verbo de movimento (eo, exeo, uenio): Tum filius tuos intro iit uidere, ut uenit, quid agat (Ter. Hec. 345) [trad.: "Então, teu filho foi lá dentro ver, desde que chegou, como ela passa"];

b) com verbo de finalidade (mitto, ago): Reddere boc non perdere erus me misit (P. Ps. 642) [trad.: "O senhor enviou-me [aqui] para devolver, não para perder isto"];

c) com verbo de doação (do, trado, ministro): Age, circumfer mulsum, bibere da (P. Pers. 821) [trad.: "Vamos!, faz circular o [vinho] melado, dá de beber"].

Nessa construção, porém, concorrem com o infinitivo outras formas nominais do verbo (MEILLET \& VENDRYES, 1979, 
p. 621). Assim, com os verbos de movimento ou finalidade constrói-se o supino em -um; com os de doação, o gerundivo; com uns e outros, o gerúndio acusativo preposicional. Por exemplo, nos seguintes passos de César (séc. I a.C.):

a) legatos ad Caesarem mittunt rogatum auxilium (CAES. G. I 11,2) [trad.: "enviam delegados a César para pedir ajuda"], o supino em -um concorre com o infinitivo final (= legatos mittunt rogare);

b) hos Haeduis custodiendos tradit (CAES. G. VI 4,4) [trad.: "entrega-os aos héduos, para serem vigiados"], o gerundivo concorre com o infinitivo final (= bos custodire tradit).

Ademais, concorrem com o infinitivo formas finitas do verbo, em regra, subjuntivas (MEILLET \& VENDRYES, 1979, p. 621). Por exemplo, nos seguintes passos de César:

a) legatos ad Dumnorigem Haeduum mittunt, ut eo deprecatore a Sequanis impetrarent (CAE. G. I 9,2) [trad.: "enviam delegados ao héduo Dumnórige, para que, a pedido dele, [o] recebessem dos séquanos"], concorre com o infinitivo (= legatos mittunt impetrare) o subjuntivo de $u t$, isto é, a oração subordinada adverbial final;

b) praemittit, qui uideant quas in partes hostes iter faciant (CAES. G. I 15,1) [trad.: "envia à frente [cavaleiros] que vejam para que lado os inimigos seguem caminho"], concorre com o infinitivo (= praemittit eos uidere) o subjuntivo de $q u i$, isto é, a oração adjetiva circunstancial.

Terêncio testemunha o modo como o uso de tais formas às vezes se confundia (MEILLET \& VENDRYES, 1979, p. 621): missast ancilla ilico obstetricem arcessitum ad eam et puerum ut adferret simul (TER. Andr. 514-5) [trad.: "a aia foi enviada lá para fazer vir a parteira, e para que ao mesmo tempo trouxesse o menino"]. Em expressões estereotipadas, tais como dare bibere [trad.: "dar de beber"], porém, o infinitivo impõe-se (BASSOLS, 
1987, v. I, p. 355) - cf. ut Ioui bibere ministraret (Cic. Tusc. I 65) [trad.: "para que servisse de beber a Júpiter"], ut bibere sibi iuberet dari (Liu. XL 47,5) [trad.: "que ordenasse dar-lhes de beber"].

Tal concorrência parece obedecer a critério sociolingüístico, de modo que o infinitivo final é empregado em contexto coloquial, e as demais formas de supino, gerundivo e gerúndio, em contexto formal. Não por acaso, aliás, dos autores supracitados, aqueles em que ocorre o infinitivo final são, por exemplo, comediógrafos, que justamente imitam a elocução coloquial (MAURER JR, 1959, p. 182). Por isso ainda, testemunham o infinitivo final autores cristãos que imitam aquela elocução (VÄÄNÄNEN, 1975, p. 222-223): ascendit in montem solus orare (Mt. 14,23) [trad.: "subiu ao monte sozinho para orar"]. Nesses, ademais, o uso do infinitivo final expande-se, prendendo-se o infinitivo, não só a verbo de movimento, mas a verbo de repouso: et sedit populus comedere ac bibere et surrexerunt ludere (Ex. 32,6) [trad.: "e o povo sentou-se para comer e beber, e levantou-se para brincar"]. Enfim, foi porque o infinitivo final foi empregado em contexto coloquial que passou ao português, ao contrário das referidas construções de supino, gerundivo e gerúndio.

Em português, pois, $O$ infinitivo final prende-se a verbos de movimento, finalidade e doação. Diferente do infinitivo latino, porém, que deve ser simples, o infinitivo português pode ser simples ou preposicional. Mais precisamente, já no português antigo, a verbos de movimento e finalidade prendem-se ora o infinitivo simples ora o preposicional (DIAS, 1933, p. 226-227): Outrossi d'Allegrete [...] lhe enviaram dizer (F. LOPEs, D. João I, 162); a verbos de doação, porém, prende-se sempre o infinitivo preposicional (DIAS, 1933, p. 227-228): Da-me de comer e de beber quanto me faz mester (Fabul. 40). Na Demanda do Santo Graal, em particular, o infinitivo ligado a verbos de movimento (ir, vir, correr) e ao verbo de finalidade enviar pode ser simples: $E$ el rei fora entam, ouvir missa a see com gram companha de cavalleiros (5, 7-8); Envia-te dizer o irmitam que este dia doje te vinrá a maior maravilha (13, 25); ou preposicional: E os cavalleiros [...] foram a elle para veerem o que era $(6,11-2) ;$ Me enviou acá [...] por filhar de vos vingança 
(32,32-3). Com os demais verbos de movimento (tornar, partir, chegar) e de finalidade (levar, trazer), porém, é de rigor o emprego da preposição: E el disse que tornava pello fazer cavalleiro $(38,20)$; Que o levava $[$ a $]$ aquel lugar pelo securar em sua guarda (48,5-6). Assim também, é obrigatória a preposição com verbo de doação, seja este empregado intransitivamente (Antes que lhe dessem de comer $(9,34)$ ), seja empregado transitivamente (E deu a Estor o escudo a levar $(102,19))$. Assim também, no português moderno, o infinitivo ligado a verbo de movimento ou finalidade pode ser simples ou preposicional, e o ligado a verbo de doação deve ser preposicional (SAID ALI, 1966, p. 338; BECHARA, 1988, p. 161-163): Diz-se que ele era um dos doze que foram a Inglaterra pelejar (HERC. Frag. 92); Porque tive fome e me destes de comer, tive sede, e me destes de beber (VIEIRA Serm. VIII 270).

$\mathrm{Na}$ verdade, também o infinitivo final preposicional o português o teria herdado do latim, onde aquele teria resultado do cruzamento da construção de infinitivo simples e gerúndio preposicional, assim: aggredior dicere vs. aggredior ad dicendum > aggredior ad dicere (ERNOUT \& THOMAS, 1953, p. 270; VÄÄNÄNEN, 1975, p. 223) [trad.: "ponho-me a dizer"]. Mesmo autores cristãos que imitam a elocução coloquial, porém, hesitam em empregar o infinitivo preposicional; por exemplo, lá onde na Itala se usa o infinitivo preposicional: dare ad manducare $(\mathrm{J} .6,53)$ [trad.: "dar de comer"], Jerônimo (séc. IV-V) todavia usa o gerúndio preposicional: dare ad manducandum (J. 6,53) [trad.: "dar de comer"]. Seja como for, em português as preposições que introduzem o infinitivo final são, bem entendido, preposições finais, a saber: $a$, para, por, de (CUNHA \& CINTRA, 1985, p. 549, 559, 561; LIMA, 1976, p. 324-327, 347, 350; PEREIRA, 1919, p. 552, 559; DIAS, 1933, p. 116-118, 124).

Mais do que isso, em português o infinitivo final acaba por compor com verbo de movimento locução verbal, de modo que o valor de finalidade do infinitivo dá lugar ao valor de posterioridade da locução. Pois, na construção: locomover-se (= verbo de movimento) para agir (= infinitivo final), embora a ação significada pelo infinitivo seja a 
finalidade do movimento significado pelo verbo principal, supõe-se ordem temporal, segundo a qual o tempo da ação do infinitivo seja posterior ao da ação do verbo de movimento. Assim, quando o infinitivo deixa de ser forma simples ligada ao verbo principal, para compor com este locução verbal, o valor final daquele dá lugar ao valor futuro desta. Assim, de um lado, em vou a São Paulo trabalhar, o infinitivo trabalhar é forma simples ligada ao verbo principal vou como adjunto adverbial de finalidade: vou (verbo principal) / a São Paulo (adjunto adverbial de lugar) / trabalhar (adjunto adverbial de finalidade), de maneira que se supõe um deslocamento (= a São Paulo) cuja finalidade seja uma ação (= trabalhar). De outro lado, em vai chover, o infinitivo chover compõe com o verbo auxiliar vai locução verbal de valor futuro, equivalente a choverá, de maneira que não se supõe deslocamento, nem finalidade, mas tão-só tempo (= futuro) (SAID ALI, 1966, 338; BECHARA, 1988, p. 162).

Essa evolução, a princípio morfológica e semântica, refletese ainda na sintaxe. Pois, na construção: vou a São Paulo trabalhar, se o verbo vou e o infinitivo trabalhar deixam de ser formas simples, cujos valores sejam respectivamente o movimento e a finalidade, e passam a compor locução verbal, cujo valor único seja a posterioridade, a preposição $a$, por sua vez, que prende $S a \tilde{o}$ Paulo a vou como adjunto adverbial de lugar de direção, passa a ser incongruente. Assim, a oração deve reconstruir-se, de modo que São Paulo deixe de indicar o lugar para onde converge a ação significada pelo verbo vou, e passe a indicar o lugar onde se consume a ação significada pela locução verbal vou trabalhar; daí, São Paulo deixa de se prender ao verbo vou por meio da preposição $a$, e passa a prender-se à locução verbal vou trabalhar por meio da preposição em: vou / a São Paulo / trabalhar > vou trabalhar / em São Paulo.

$\mathrm{Na}$ Demanda do Santo Graal, por exemplo, o infinitivo pode compor locução verbal com o verbo principal: $E$ de grado os iria partir se podesse (123, 4-5). De fato, o infinitivo partir não se constrói como adjunto adverbial de finalidade do verbo principal 
iria (= "iria para separá-los"), mas compõe locução verbal com o verbo auxiliar iria (= "separá-los-ia"). Ainda na Demanda, tal alteração morfológica reflete-se na sintaxe, de modo que, quando o infinitivo se constrói como adjunto adverbial de verbo principal de movimento, uma preposição de movimento introduz o nome que significa o lugar para onde converge a ação significada pelo verbo; quando, porém, o infinitivo compõe locução verbal com verbo auxiliar, uma preposição de situação introduz o nome que significa o lugar onde se consume a ação significada pela locução. Assim, neste passo da novela E el rei fora entam ouvir missa aa see com gram conpanba de cavalleiros $(5,7-8)$, há dois adjuntos adverbiais, a saber: um de finalidade, que é o infinitivo ouvir, e outro de lugar de direção, que é introduzido pela preposição $a$ (= aa see). Neste outro - Foi ouvir missa na capella del rei $(24,16)$-, porém, há locução verbal (= foi ouvir), a que se prende um único adjunto adverbial de lugar de situação, introduzido pela preposição em (= na capella).

\section{Infinitivo objetivo}

Se bem que a princípio o infinitivo fosse forma nominal pura de ablativo em - $e$ ou dativo em $-i$, construindo-se como adjunto adverbial de finalidade de um verbo principal, o falante reinterpretou a forma do infinitivo, passando a empregá-lo em construções muito diferentes da original. Ora, porque, como disse, o infinitivo tendeu a empregar-se em expressões estereotipadas, o aspecto e valor desinencial daquele apagaram-se para o falante, que passou a tratá-lo como nome indeclinável; em outras palavras, fossilizou-se a desinência casual do infinitivo. ${ }^{4}$ Assim, o falante passou a tratá-lo como substantivo neutro do caso reto, o que lhe

\footnotetext{
${ }^{4}$ Tal fenômeno é comum a outros nomes. Por exemplo, o substantivo modus, habitualmente empregado no ablativo, tendeu a fixar-se nesse uso, de tal modo que se fossilizou a desinência casual, e o substantivo modo passou a advérbio.
} 
abriu o caminho para construir-se como acusativo, isto é, como objeto direto de verbo principal (BASSOLS DE CLIMENT, 1987, p. 347). A vitalidade dessa construção verifica-se ao longo de toda a história do latim (VÄNÄÄNEN, 1975, p. 222; MAURER JR, 1959, p. 183). No contexto formal, em particular, o uso do infinitivo objetivo acabou por prevalecer sobre o uso original do infinitivo final, que, naquele contexto, como disse, foi substituído pelo uso do supino, gerúndio ou gerundivo (MEILLET \& VENDRYES, 1979, p. 621-622; ERNOUT \& THOMAS, 1953, p. 255).

$\mathrm{Na}$ verdade, por ter sido tratado como substantivo indeclinável, o infinitivo pôde ocupar as mais diversas posições que caberiam não só ao acusativo, mas também aos outros casos adverbiais, isto é, ao ablativo e ao dativo. Assim, de um lado, verbos como uolo, nolo, malo, que de fato se construíam com substantivo acusativo (CIc. Verr. III 196: Nummos uolo [trad.: "quero moedas"], admitiram infinitivo (CAES. G. III 7,1: Regiones cognoscere uolebat [trad.: "queria fazer o reconhecimento das regiões"]). De outro lado, verbos como cesso, abstineo, desisto, que a princípio se construiriam com substantivo ablativo (Liv. II 47,2: ille graui uolnere ictus ex acie cessit [trad.: "aquele, abatido por grave ferimento, desistiu da batalha"]), admitiram ainda infinitivo (CIC. $Q$. II 2,1: Cyrum urgere non cesso "não desisto de insistir com Ciro"). Verbos como studeo, consuesco, soleo, que a princípio se construiriam com substantivo dativo (CAES. G. VI 22,1: Agri culturae non student [trad.: "Não se empenham no cultivo do campo"]), admitiram ainda infinitivo (CIC. De or. I 107: Ego uero [...] istis obsequi studeo [trad.: "Eu, de minha parte, $[\ldots]$ empenho-me em seguir esses"]). Seja como for, ao lado de todos esses verbos, o infinitivo foi tratado como acusativo, isto é, como objeto direto do verbo principal (ERNOUT \& THOMAS, 1953, p. 257-8; BARRETO, 1980, p. 208-9, 213-214).

Em suma, o infinitivo passou a construir como acusativo ou objeto direto dos seguintes verbos (MEILLET \& VENDRYES, 1979, p. 624; RIEMANN, 1942, p. 319-320, 327-336; ERNOUT \& THOMAS, 1953, p. 257-258, 321-2, 328-331): 
a) verbos volitivos (uerba uoluntatis: [vontade] uolo, nolo, malo; [desejo] cupio, opto, desidero; [intenção] statuo, constituo, decerno; [esforço] studeo, contendo, audeo; [pressa] festino, maturo, propero; [repulsa] metuo, caueo, timeo, uereor; [hesitação] dubito, moror): p. ex., qui secundum naturam uolent uiuere (CIc. Off. III 23,11) [trad.: "que quererão viver segundo a natureza"];

b) verbos acurativos (uerba agendi: [início da ação] incipio, coepi, ordior; [fim da ação] cesso, mitto, abstineo, desino; [repetição da ação] soleo, consuesco): p. ex., Caesar [...] maturat ab urbe proficisci (CAES. G. I 7,1) [trad.: "César [...] apressa-se para sair da cidade"];

c) verbos de possibilidade (possum, queo, nequeo, scio, nescio, disco): p. ex., sine qua administrari ciuitas non potest (CIC. Off. I 88,11) [trad.: "sem a qual não se pode administrar a cidade"];

d) verbos de necessidade (debeo): p. ex., Numne [...] ferre contra patriam arma [...] debuerunt? (CIc. Lae. 36) [trad.: "Não é verdade que não [...] deviam [...] ter apontado armas as contra a pátria?”].

Em português, o infinitivo continua a construir-se como objeto direto de verbos volitivos e acurativos, verbos de possibilidade e de necessidade. Assim como o infinitivo final, porém, assim o infinitivo objetivo português afasta-se do latino, na medida em que este é, invariavelmente, simples, e aquele é ora simples ora preposicional. Assim, no português antigo (DIAS, 1933, p. 219-22; SAID ALI, 1966, p. 339-40), o infinitivo constrói-se como objeto direto:

a) com verbos volitivos ([sem preposição] querer, tencionar, propor-se; [com preposição] acertar de, antecipar-se a, apressar-se a, hesitar em, insistir em, teimar em, tardar em/ $a$; [preposição facultativa] assentar [em], punbar [em/de], desejar [a/de], atrever-se [a/de], ousar [a/de], ser ousado [a/ de]): p. ex., Não havia algum que se atrevesse de o levar á India (BARROS Hist. I 4,5), Atrevo-me eu descobrir (CEITA 18); 
b) com verbos acurativos ([sem preposição] costumar; [com preposição] acabar de, cessar de, deixar de, deixar-se de, continuar a, tornar a, por-se a, filbar-se a, entrar al de; [preposição facultativa] soer [a], começar [a/de]): p. ex., E começou [...] perguntar que gente era e que buscavão (BARros Hist. I 4,3), Começarom todas de fugir (Fabul. 57);

c) com verbos de possibilidade ([sem preposição] poder, saber; [com preposição] aprender a) e de necessidade ([com preposição] ter de/a; [preposição facultativa] haver $[a / d e]$, dever $[a / d e])$ : p. ex., Tempo em que o devem a filhar (GIR. Alv. 2), Valéra entendia que se deviam exigir outras condições mais (BARROS Hist. 1 154).

Na Demanda do Santo Graal, em particular, o infinitivo objetivo constrói-se do seguinte modo:

a) com verbos volitivos:

- ambos os infinitivos:

desejar (a/de): Nunca tanto desejei rem como veer o bõo cavalleiro (34,1-2); Que [sc. Gallaaz] tanto desejamos a veer $(12,22)$; Que nom desejarei tanto cousa como de morrer por mão de tam bõo cavalleiro $(29,27-8)$;

ousar (a/de), ser ousado (a/de): Mais nom no ousava mostrar $(6,23)$; E el nom no ousou a descobrir a nenhũu de seus vassallos $(53,12-3)$; Que nenhũu do linhagem de rei Artur seja ousado de entrar dentro (84,1-2);

cuidar (a/de): Se vos nom cuidades seer bõo homem ou bõo cavalleiro $(2,32)$; Se aqui cuidasse a morrer $(8,10)$; Nom vejo eu i tal cousa por que o nom cuidasse de vencer (51,6-7);

querer (a): Quando queriam poer as mesas $(1,6)$; Eu a justar quero $(338,10)$. 
- infinitivo preposicional:

guisar-se de, ser guisado de: (E) quando os virom [...] já quisados de ferirem e de se defenderem $(76,9-10)$; E guisouse de mostrar gram bondade d'armas (102,5-6);

trabalhar-se de: Que [sc. clerigos] se trabalhavam de catar as seedas da tavola redonda $(8,18)$;

esforçar-se para: Esforçou-se para fazer-lhes milhor continente $(80,15)$.

b) com verbos acurativos:

- ambos os infinitivos:

começar (a/de): E começou ende sair ũa voz tam strosa $(38,28-9)$; Ella começou a catar de ũa parte e da outra do paaço $(1,8-9)$; E começou-se de ir $(78,26)$;

soaer (a): As aventuras soiam avir aas festas grandes (5,32-3); Nom soiades vos a comer $(5,27)$;

leixar (a/de), leixar-se (a/de): E leixarom i fallar $(29,15)$; Te leixei de matar $(30,23)$; Nem nos nom no leixaremos a contar $(123,33-4)$.

- ambos os infinitivos:

filhar a, filhar-se a: Entom se filharom [a] andar (2,4-5);

meter-se a: E meterom-se a busca-la $(63,11)$;

quedar de: Nom quedou de chorar $(3,13-4)$;

quitar-se de: E Persival disse que se nam podia quitar de ir depollo cavalleiro $(136,15-6)$;

scusar-se de: Que se nom pode scusar de dar ũu Dom (43,3);

sofrer-se de: E sabede que [...] se nom pode sofrer de chorar $(4,7-8)$;

deter-se de: Ca nom prazia a Deos de se mais deteer de ir (125,4-5);

guardar-se de: Certas muito vos deveriades de guardar de dizer cousa $(76,25-6)$;

tornar a: Tornou a seu pensar e a chorar como ante $(80,13)$. 
c) com verbos de possibilidade e de necessidade:

- ambos os infinitivos:

saber (em): Se avia i algũu que soubesse guarecer chagas (48,9-10);

Emquanto nom sabem em studar (42,6);

dever (a/de): Tu te devias ora mais guardar $(28,17)$; Vo-lo deviades

de fazer (2,22-3); Muito deviamos a seer ledos $(16,29)$;

haver (a/de): A poucas horas averemos conprar sua morte caramente (76,2-3); Aquel que o há de matar (131,32); E outro lhe matou o cavallo, assi que ele ouve a ir a terra $(118,24-5)$.

- infinitivo preposicional:

ter a/de, ser teudo a/de: Ca [...] tinha a donzella de rogar o cavalleiro (72,25-6); Ca teudo som de vos fazer serviço $(1,19)$; Ca muito erades vos teudo a servir nosso Senhor ca outros muitos $(146,20-1)$.

Enfim, este passo da novela ilustra bem a convivência dos usos simples e preposicional do infinitivo ligado ao verbo começar: E Glifet [...] começou de ir apos ella. E [...] começou-se a sinar pella ligeirice que lhe vio. [...] Começou ir em pos ella $(65,29-35)$.

Assim também, no português moderno (SAID ALI, 1966, p. 343-50; BECHARA, 1992, p. 111-3):

a) com verbos volitivos ([vontade ou desejo] querer, desejar, odiar, abominar; [intenção ou esforço] pretender, buscar, tentar, ousar, atrever-se a, esforçar-se por; [consecução] conseguir, lograr): p. ex., Um tomo houvéramos de encher, a querermos miudar e exemplificar todas as variedades de composição métrica (CASTILHO Metr. 146);

b) com verbos acurativos ([início da ação] começar a, pôr-se $a$; [duração da ação] continuar $a$; [repetição da ação] tornar a, costumar, soer; [fim da ação] cessar de, deixar de, acabar de, parar de, vir de): p. ex., Mas a selva começa a rarear (HERC. Eur. 227); 
c) com verbos de possibilidade (poder, saber) e de necessidade (dever, haver de, ter de, precisar de): p. ex., Bem lhe pode o principe negar o que lhe elles pedirem (VIEIRA Serm. II 97); Deviam-no trazer todos vocês na palma (CASTILHo Tart. 11).

Ora, é para atentar na preposição que introduz ou acompanha o infinitivo objetivo. Antes de tudo, pode ser conectiva e obrigatória, ou expletiva e facultativa; lá, o infinitivo é objetivo indireto, e aqui, objetivo direto. Assim, de um lado, o verbo escapar é transitivo indireto, a que se prende complemento por meio da preposição de, em Quando do ferro as vidas escapauão (САM. Lus. III 113,8); logo, em Que seo facundo Vlysses escapou, / De ser na Ogigia ilha, eterno escrauo (CAM. Lus. II 45,1-2), o infinitivo ser é objeto indireto do verbo principal escapou, e a preposição de é conectiva. De outro lado, o verbo aprender é transitivo direto, a que se prende complemento sem o concurso de preposição, em [...] quem sempre com pouco experto peito / Razões aprende [...] (CAM. Lus. VII 86,5-6); logo, em E porque os que ouuirem daqui aprendão / Afazer feitos grandes de alta proua (CAM. Lus. VI 42,5-6), o infinitivo fazer é objeto direto do verbo principal aprendão, e a preposição $a$ é expletiva. Assim também, é expletiva a preposição que acompanha o infinitivo ligado ao verbo desejar, transitivo direto, de modo que ora ocorra - Segundo o que desejas de saber (CAM. Lus. III 5,6) - ora não ocorra - [...] que o Mouro ver deseja (CAM. Lus. II 106,2). O emprego da preposição expletiva, porém, pode variar com o tempo; assim, ora convivem os usos simples e preposicional do infinitivo, ora um acaba por prevalecer sobre o outro (SAID ALI, 1966, p. 339340; DIAS, 1933, p. 219-222; PEREIRA, 1919, p. 496; BARRETO, 1980, p. 203-204). Por exemplo, o verbo começar, no português antigo, constrói-se ora com o infinitivo simples (começar fallar), ora com o preposicional (começar a fallar); no português moderno, porém, prevalece o uso preposicional (SAID ALI, 1966, p. 339-40). Já a construção do verbo dever hesita ainda hoje entre o uso simples (deve ser) e o preposicional (deve de ser) (SAID ALI, 1966, p. 340). 
Ademais, é para atentar na forma e sentido das preposições expletivas que acompanham o infinitivo objetivo direto, pois são as mesmas que acompanham o infinitivo final, a saber: $a$, de, para e por, isto é, preposições que podem significar "finalidade". Pois em latim o uso preposicional dos nomes concorreu com as formas casuais, de modo que em português acabou por suplantá-las (MEILLET \& VENDRYES, 1979, p. 526; ERNOUT \& THOMAS, 1953, p. 9-10; PEREIRA, 1919, p. 550; DIAS, 1933, p. 108-109; SAID ALI, 1966, p. 203). Em outras palavras, as preposições $a$, de, para e por acompanham o infinitivo explicitando o valor final que outrora fora significado pela desinência casual daquele (ERNOUT \& THOMAS, 1953, p. 270). ${ }^{5}$ Por isso, não são, como se disse, constituinte sintático do verbo principal, mas constituinte morfológico do infinitivo, de modo que, na verdade, podem acompanhar não só o infinitivo que é objeto direto, mas também aquele que é sujeito (BASSOLS DE CLIMENT, 1987, v. I, p. 350, n. 7; DIAS, 1933, p. 219; SAID ALI, 1966, p. 340-341; BARRETO, 1980, p. 210-212): Nõ era cousa convinhavil de tu morreres agora (BARLÃ̃O 45); Seria bom de birem a Mancor (ZURARA CM 408); A elles convinba de saber (Liv. Mont. 47); Nom era bem de o assi cercarem (Liv. Mont. 192); Custou-lhe muito a aceitar a casa (M. Assis BC 94).

No português moderno, porém, ao contrário do uso preposicional do infinitivo objetivo, tende a escassear o do subjetivo (SAID ALI, 1966, p. 340; BECHARA, 1992, p. 237).

Por fim, assim como o infinitivo final, assim o objetivo tende a compor locução verbal com verbo de possibilidade ou de necessidade e com verbo volitivo ou acurativo (BECHARA, 1992, p. 110-112). Ademais, assim como o infinitivo final, o infinitivo objetivo compõe com verbo volitivo ou de necessidade locuções

\footnotetext{
${ }^{5}$ Tal é a explicação da forma do infinitivo inglês, cujo componente to outra coisa não é que preposição de valor igual ao de ad (BASSOLS DE CLIMENT, 1987 , v. I, p. 347 , n. 1; BARRETO, 1980, p. 220-221).
} 
verbais que se especializam no valor de posterioridade (GRANDGENT, 1952, p. 99-100; MAURER JR, 1959, p. 125). Tais locuções concorrem com as formas de futuro simples em latim, de modo que acabam por suplantá-las em português.

A locução verbal de habeo e infinitivo merece atenção particular, dada a importância dela para a constituição da conjugação verbal do português. Ora, em latim, em contexto formal, a locução de habeo e infinitivo tem valor de possibilidade, e não de necessidade (RIEMANN, 1942, p. 335, n. 2): Quid habes igitur dicere? (Cic. Balb. 35) [trad.: "Que tens, pois, para dizer?"]; em contexto coloquial, porém, adquire valor de posterioridade, e assim é empregada no latim cristão (ERNOUT \& THOMAS, 1953, p. 252): Tempestas illa tollere habet totam paleam de area (Aug. Eu. Ioh. IV 1,2) [trad.: "Aquela tempestade há de levantar do chão toda a palha"]. Logo, em latim, a locução de habeo e infinitivo acaba por concorrer com as formas de futuro simples. Em português, por sua vez, a locução pode ter o valor de obrigatoriedade, como, por exemplo, neste passo da Demanda do Santo Graal - Ouveram lhe outorgar o que el quise $(48,30)$-, em que o sentido da locução é: "foram obrigados a outorgar". No mais das vezes, porém, tem o valor de posterioridade, como, por exemplo, neste outro passo da Demanda:-Aquel que o há de matar $(131,32)$-, em que o sentido da locução é: "aquele que o matará", e não: "aquele que é obrigado a matá-lo". Mais que isso, porém, o verbo bei tendeu a fixar-se em posição posterior à do infinitivo; depois, este e aquele acabaram por fundir-se numa única palavra: valer há $>$ valerá. Assim, pois, se constituíram as formas portuguesas do futuro, ou melhor, do chamado futuro do presente; as formas do futuro do pretérito, por sua vez, ter-se-iam formado a partir das formas do pretérito imperfeito de haver por analogia: valer há > valerá :: valer hia > valeria (SAID ALI, 1966, p. 143; MAURER JR, 1959, p. 129; PEREIRA, 1919, p. 162; CUNHA \& CINTRA, 1985, p. 382; PEREIRA, 1919, p. 502). Note-se, porém, que a fusão do verbo bei e do infinitivo nem sempre se completou cabalmente no português antigo, em que, a par de tornarei-me, podia dizer-se ainda tornar-me-ei, intercalando- 
se o pronome pessoal átono entre o verbo bei e o infinitivo (GRANDGENT, 1952，p. 101; NUNES，1956，p. 317-318; COUTINHO, 1974, p. 276-277). Por exemplo, neste passo da Demanda - Tornarei-me entam (17,10-1) -, o infinitivo tornar e o verbo auxiliar hei estão perfeitamente soldados; neste outro $-E$ depois conselhar-vos-ei $(19,3)$-, porém, o pronome vos interpõese entre o infinitivo e o verbo auxiliar. Tal linguagem persiste no português moderno, e só a análise histórica permite explicar a colocação mesoclítica do pronome junto às formas de futuro, único caso de tmese do vernáculo (SAID ALI, s/d, p. 496).

Enfim, registre-se que a locução verbal de ter e de infinitivo também se especializou no valor de posterioridade, de modo que concorre com a locução verbal de haver e infinitivo. Todavia, a despeito do valor temporal comum, as locuções expressam aspectos distintos, pois a locução de haver equivale a um futuro promissivo (bei de fazer = "prometo que farei"), e a de ter, a um futuro obrigatório (tenbo de fazer = "sou obrigado a fazer") (SAID ALI, 1966, p. 162-3; PEREIRA, 1919, p. 496). ${ }^{6}$ Ora, é bem esse o valor da locução neste passo da Demanda - Saio de seu leito [...] com gram pesar de que avia de fazer contra sua vontade o que lhe Amor mandava, ca [...] tinha a donzella de rogar o cavalleiro (72,23-6) -, em que tinba de rogar é a explicação do que a donzela avia de fazer contra a sua vontade, isto é, por obrigação. ${ }^{7}$

${ }^{6}$ A par destas, outras locuções de verbo de necessidade e infinitivo especializaram-se igualmente na noção de posterioridade: por exemplo, a de dever e infinitivo. Na Demanda do Santo Graal, em particular, essa locução pode ter o valor de necessidade, como neste passo - Vo-lo deviades de fazer $(2,22-3)$-, em que o sentido da locução é: "vós tínheis a obrigação de fazer". No mais das vezes, porém, tem o valor de posterioridade, como neste passo Se poderdes achar o cavaleiro que deve a dar cima aas venturas do regno de Logres (276,15-7), em que o sentido da locução é "o cavaleiro que dará cima", e não "o cavaleiro que tem a obrigação de dar cima".

${ }^{7}$ Apesar do exemplo da Demanda, alguns gramáticos pretendem que a locução de ter e infinitivo date do séc. XVIII (SAID ALI, 1966, p. 162-163). 


\section{Conclusão}

Em latim, o infinitivo é, a princípio, forma nominal pura, ou melhor, nome de ação que se declina no ablativo ou dativo de finalidade; assim, prende-se como adjunto adverbial a verbo de finalidade ou de movimento, para expressar a finalidade da ação ou o termo do movimento. Posteriormente, o infinitivo foi tratado como substantivo neutro do caso reto; então, passou a construirse como acusativo, isto é, como objeto direto de verbo volitivo ou acurativo, verbo de possibilidade ou necessidade. Em português, o infinitivo final pode prender-se ao verbo ou diretamente ou por meio de preposição final: $a$, de, para e por; além disso, costuma compor locução verbal, em que o valor circunstancial de finalidade acaba por ceder ao valor temporal de futuro. O infinitivo objetivo, por sua vez, pode prender-se ao verbo ou diretamente ou por meio de preposição; esta, porém, pode ser ou conectiva e obrigatória, ou expletiva e facultativa, de modo que lá o infinitivo seja objetivo indireto, e aqui objetivo direto. Além disso, o infinitivo objetivo pode compor locução verbal; na locução de haver e infinitivo, em particular, o valor circunstancial acaba por ceder ao valor temporal de futuro.

\section{Referências}

\section{Gramáticas latinas}

BASSOLS DE CLIMENT, M. Sintaxis latina. Madrid: C.S.I.C., 1987. 2 v. BUCK, C. D. Comparative grammar of greek and latin. Chicago: The University of Chicago Press, 1962.

ERNOUT, A. Morphologie historique du latin. Paris: Klincksieck, 1974.

ERNOUT, A.; THOMAS, F. Syntaxe latine. Paris: Klincksieck, 1953.

GRANDGENT, C. H. Introducción al latín vulgar. Madrid: C.S.I.C., 1952. 
MAURER JR, T. H. Gramática do latim vulgar. Rio de Janeiro: Acadêmica, 1959.

MEILLET, A.; VENDRYES, J. Traité de grammaire comparée des langues classiques. Paris: Honoré Champion, 1979.

RIEMANN, O. Syntaxe latine. 7. ed. Paris: Klincksieck, 1942.

VÄÄNÄNEN, V. Introducción al latín vulgar. Madrid: Gredos, 1975.

\section{Gramáticas portuguesas}

BARRETO, M. Novíssimos estudos da língua portuguesa. 3. ed. Rio de Janeiro: Presença / INL-FCRB-MEC, 1980.

BECHARA, E. Lições de português pela análise sintática. Rio de Janeiro: Padrão, 1988.

BECHARA, E. Moderna gramática portuguesa. São Paulo: Companhia Editora Nacional, 1992.

COUTINHO, I. L. Pontos de gramática histórica. 6. ed. 7. imp. Rio de Janeiro: Acadêmica, 1974.

CUNHA, C.; CINTRA, L. Nova gramática do português contemporâneo. 2. ed. 6. imp. Rio de Janeiro: Nova Fronteira, 1985.

DIAS, E. S. Syntaxe bistorica portuguesa. Lisboa: Livraria Clássica, 1933.

LIMA, R. Gramática normativa da língua portuguesa. 18. ed. Rio de Janeiro: José Olympio, 1976.

NUNES, J. J. Compêndio de gramática histórica portuguesa. Lisboa: Livraria Clássica, 1956.

PEREIRA, E. C. Grammatica bistorica. 2. ed. São Paulo: Companhia Editora Nacional, 1919.

SAID ALI, M. Grammatica secundaria da lingua portugueza. São Paulo: Melhoramentos, s/d.

SAID ALI, M. Gramatica historica da língua portuguêsa. São Paulo: Melhoramentos, 1966. 


\section{Edições}

CAMÕES, L. de. Os Lusíadas. Reprodução paralela de duas edições de 1572 [fac-símile]. Comissão da Acadêmia das Ciências de Lisboa para a edição crítica de Os Lusíadas. Lisboa: Imprensa Nacional-Casa da Moeda, 1982.

DEMANDA do Santo Graal. Edição crítica de Joseph-Maria Piel e Irene Freire Nunes. Lisboa: Imprensa Nacional-Casa da Moeda, 1988.

Recebido para publicação em 31 de agosto de 2012 Aprovado em 18 de novembro de 2012 